\title{
Effect of remote ischemic preconditioning in the expression of IL-6 and IL-10 in a rat model of liver ischemia-reperfusion injury ${ }^{1}$
}

\author{
Marco Antonio Correa Guimarães Filho ${ }^{\mathrm{I}}$, Erika Cortez ${ }^{\mathrm{II}}$, Érica Patrícia Garcia-Souza ${ }^{\mathrm{III}}$, Vivian de Melo Soares ${ }^{\mathrm{IV}}$, Aníbal Sanchez \\ Mourav, Laís Carvalhovi, Maria Cristina de Araujo Maya $^{\text {VII }}$, Marcos Bettini Pitombo ${ }^{\text {III }}$
}

DOI: http://dx.doi.org/10.1590/S0102-865020150070000002

${ }^{I}$ Master, Department of General Surgery, Universidade Estadual do Rio de Janeiro (UERJ), Brazil. Conception and design of the study, technical procedures, statistical analysis, manuscript preparation and writing.

IIPhD, Associate Professor, Department of Histology and Embryology, UERJ, Rio de Janeiro-RJ, Brazil. Histopathological examinations, technical procedures, interpretation of data, statistical analysis, manuscript writing.

IIIPhD, Associate Professor, Department of Physiological Sciences, UERJ, Rio de Janeiro-RJ, Brazil. Technical procedures, interpretation of data, statistical analysis, critical revision.

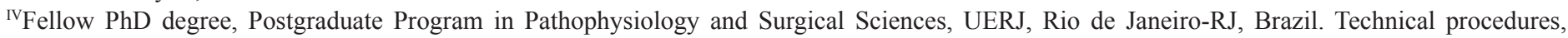
acquisition and interpretation of data.

vPhD, Associate Professor, Department of Physiological Sciences, UERJ, Rio de Janeiro-RJ, Brazil. Technical procedures, interpretation of data, statistical analysis.

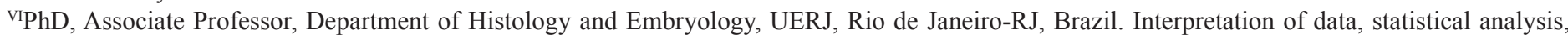
manuscript writing.

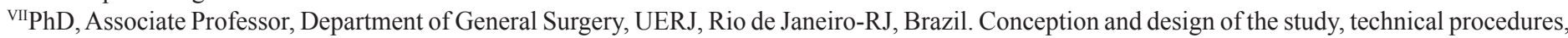
statistical analysis, final approval.

VIIIPhD, Associate Professor, Department of General Surgery, UERJ, Rio de Janeiro-RJ, Brazil. Conception and design of the study, technical procedures, statistical analysis, critical revision, final approval.

\section{ABSTRACT}

PURPOSE: To study the effect of remote ischemic preconditioning (RIPC) in ischemia-reperfusion (I/R) liver injury and in the expression of IL-6 and IL-10 in a rat model.

METHODS: Thirty-six male rats were divided in three groups: Sham; I/R injury, a 45 minutes lobar liver ischemia and reperfusion; and RIPC, six cycles of four minutes of ischemia and four minutes of reperfusion on the right hindlimb followed by a 45 minutes lobar liver ischemia and reperfusion. Tissue and blood samples were collected after $1 \mathrm{~h}$ and $3 \mathrm{~h}$ of reperfusion for histopathological study, plasma cytokines and alanine aminotransferase (ALT) measurement.

RESULTS: The histopathological study demonstrated a significant reduction in liver necrosis in the RIPC group ( $p<0,001$ ). The ALT levels were also significant lower in the RIPC group $(p<0.01)$. The cytokines assessment showed that IL- 6 levels were increased in the RIPC group after $1 \mathrm{~h}$ of reperfusion, in comparison to the I/R group $(\mathrm{p}<0.05)$. Interleukin-10 levels in RIPC groups did not differ significantly from I/R group.

CONCLUSIONS: Remote ischemic preconditioning is effective in decreasing liver necrosis in a rat model of ischemia-reperfusion. The IL-6 expression is up-regulated and peaked at $60 \mathrm{~min}$ of reperfusion. There was no difference in IL-10 expression between the groups.

Key words: Ischemic Preconditioning. Reperfusion Injury. Interleukin-6. Interleukin-10. Rats. 


\section{Introduction}

Liver transplantation is the only effective treatment for end-stage liver disease and selected cases of hepatocellular carcinoma. Ischemia/reperfusion injury (IRI), defined as cellular damage secondary to oxygen deprivation that is aggravated by the sudden restoration of blood perfusion, is a well-established pathophysiological mechanism responsible for poor early graft function and primary graft non-function ${ }^{1}$.

Several strategies have been developed to protect the graft from IRI. Those include pharmacological interventions, alternative preservation solutions, machine-perfusion and organ preconditioning ${ }^{2}$.

The most studied method of mechanical preconditioning is ischemic preconditioning (IP), defined as a brief ischemic insult, by the means of a temporary liver pedicle clamping, followed by a short reperfusion phase. The objective is to render the organ more resistant to a longer ischemic and reperfusion period ${ }^{3}$. Numerous studies in small animals showed clear beneficial effects of IP in the prevention of IRI, with improvement in biochemical parameters, such as serum transaminases, bilirubin and albumin, and survival ${ }^{4}$. As a result of those findings, several trials were conducted to evaluate IP in the clinical setting. Besides some variations in the endpoints used, the outcomes were similar, with improvement in biochemical markers but without a reduction in morbidity or mortality ${ }^{5}$.

These results stressed the need for new interventions to reduce liver IRI, as it represents a major drawback to expanding the pool of liver donors and is responsible for a significant morbidity and mortality after complex liver resections.

A novel method of preconditioning, remote ischemic preconditioning (RIPC) was described by Przyklenk ${ }^{6}$, and is defined as a brief ischemic episode on an organ or tissue that subsequently affords protection to a remote organ or tissue. Since this initial study, RIPC have been used in various experimental models with promising results.

More recently, several investigators studied the use of RIPC to reduce liver I/R injury ${ }^{7-10}$. All studies showed a protective effect in liver IRI, but the underlying mechanisms involved in RIPC have not yet been established ${ }^{11}$.

The cytokines are important mediators of the IRI. They are directly involved in cellular death, in the systemic response to the IRI, in the down-regulation of the liver IRI and even as an initial stimulus to liver regeneration. Several papers evaluated their role in the pathophysiology of liver IRI and the effects of different intervention in their expression, but none of these papers studied the influence of RIPC in cytokine expression ${ }^{12}$.
In the present work, we examined the effect of RIPC in liver injury, using histopathological study, serum ALT examination and the serum levels of IL- 6 and IL-10 during the early phase of reperfusion (up to 180 minutes) in a rat model of liver IRI.

\section{Methods}

This study was held in the Laboratory of Experimental Surgery, Universidade Estadual do Rio de Janeiro (UERJ) after approval by the local Institutional Ethics Committee (CEUA/035/2011). All the procedures were performed in agreement with the Brazilian rules on the use of animals for research ${ }^{13}$.

Thirty-six male Sprague Dawley rats, weighing 250$280 \mathrm{~g}$ were used. All animals had unrestricted access to standard laboratory diet and water ad libitum pre- and postoperatively. They were housed 5 per cage and kept under standard conditions at a room temperature of $22-24^{\circ} \mathrm{C}$ with a $12 \mathrm{~h}$ light $/ 12 \mathrm{~h}$ dark cycle. Before surgery, they were divided into three groups of 12 rats each: Sham; I/R Group and RIPC Group.

\section{Operative procedures}

There was no preoperative fasting period and no antibiotics were given. Procedures were performed by the same surgeon under sterile conditions after intramuscular anesthesia with $75 \mathrm{mg} / \mathrm{kg}$ ketamine and $5 \mathrm{mg} / \mathrm{kg}$ xylazine.

\section{I/R Injury model}

A $4 \mathrm{~cm}$ midline laparotomy was performed and the portal pedicle to the left and medial lobes was identified. A microvascular clamp was applied rendering approximately $70 \%$ of the liver ischemic as described by Yamauchi ${ }^{14}$. After 45 min the clamp was removed for liver reperfusion.

\section{$\underline{\text { RIPC model }}$}

A $2 \mathrm{~cm}$ incision in the anteromedial aspect of the right thigh and the vascular bundle to the right hindlimb was meticulously isolated. A RIPC protocol of six cycles of 4 min of ischemia followed by 4 min of reperfusion was used.

\section{Experimental design}

The animals in the I/R group were subjected only to the $\mathrm{I} / \mathrm{R}$ procedure; in the RIPC group, RIPC technique was followed by the I/R procedure; and the Sham group was not subjected to any ischemic insult, only a laparotomy with liver mobilization. 
In each group, six rats were killed after $60 \mathrm{~min}$ of reperfusion and the other six after $180 \mathrm{~min}$ of reperfusion; all by an anesthetic overdose. The liver lobes subject to the IRI were collected before the animals were killed and immediately fixed in $10 \%$ formalin solution for histological analysis. Blood were also collected and the plasma separated by a standard protocol and kept frozen at $-80^{\circ} \mathrm{C}$.

\section{Histopathological study}

Fragments of liver were fixed in $10 \%$ buffered formalin, $\mathrm{pH} 7.4$, embedded in paraffin, sectioned into $5 \mu \mathrm{m}$ slices, and stained with hematoxylin-eosin (HE), using standard histological techniques. Digital images were acquired at random in a blinded manner under a Olympus BX53 light microscope equipped with a CCD camera. Fifteen digital images per animal were studied using a semi-quantitative score that evaluates eight histological criteria: neutrophil infiltration, necrosis, cytoplasmic eosinophilia, discohesive hepatocytes, liver cell ballooning, cytoplasmic vacuolization, nuclear pyknosis and red blood cell extravasation ${ }^{10}$.

\section{Cytokine assessment}

The cytokines (IL-6 and IL-10) were measured using commercially available ELISA kits (Uscn Lifesciences, Texas, USA) according to the manufacturer's instructions. Samples were assessed in duplicate and concentrations were calculated using a standard curve.

\section{Plasmatic alanine aminotrasferase}

Plasmatic alanine aminotransferase levels were measured by a commercially available kit (Bioclin, $\mathrm{MG}$, Brazil) according to the manufacturer's instructions.

\section{Statistical analysis}

Discrete variables are reported as frequencies (n) and percentages (\%). Continuous variables were presented using means \pm SEM.

One-way analysis of variance (ANOVA) was used to compare differences among the groups regarding the citokines and ALT levels, with post hoc multiple comparisons with Holm-Sidak test.

Differences among groups with respect to the histological grading (non-normally distributed variables) were compared with the Kruskal-Wallis test, whereas pos-hoc pairwise differences were compared with the Dunn test.

All analyses were performed using the GraphPad Prism 6.0 software (GraphPad, California, USA). $\mathrm{p}<0.05$ was considered statistically significant.

\section{Results}

\section{Hindlimb RIPC reduces $I / R$ - induced liver necrosis}

To determine whether the application of RIPC could reduce the liver IRI, the histological scores of the three groups were compared. The results are summarized in Figure 1. The Sham group showed minimal tissue injury in all histopathological features of liver injury. The most relevant result was the necrosis evaluation (Figures 1 and 2). The RIPC group had a significant reduction in cellular necrosis compared to the I/R Group (1h: 3.56 vs 0.33 ; 3h: 3.56 vs 0.72 ; $\mathrm{p}<0.001)$. In the other seven features, $\mathrm{I} / \mathrm{R}$ and PCIR groups showed no significant difference in the score values. 

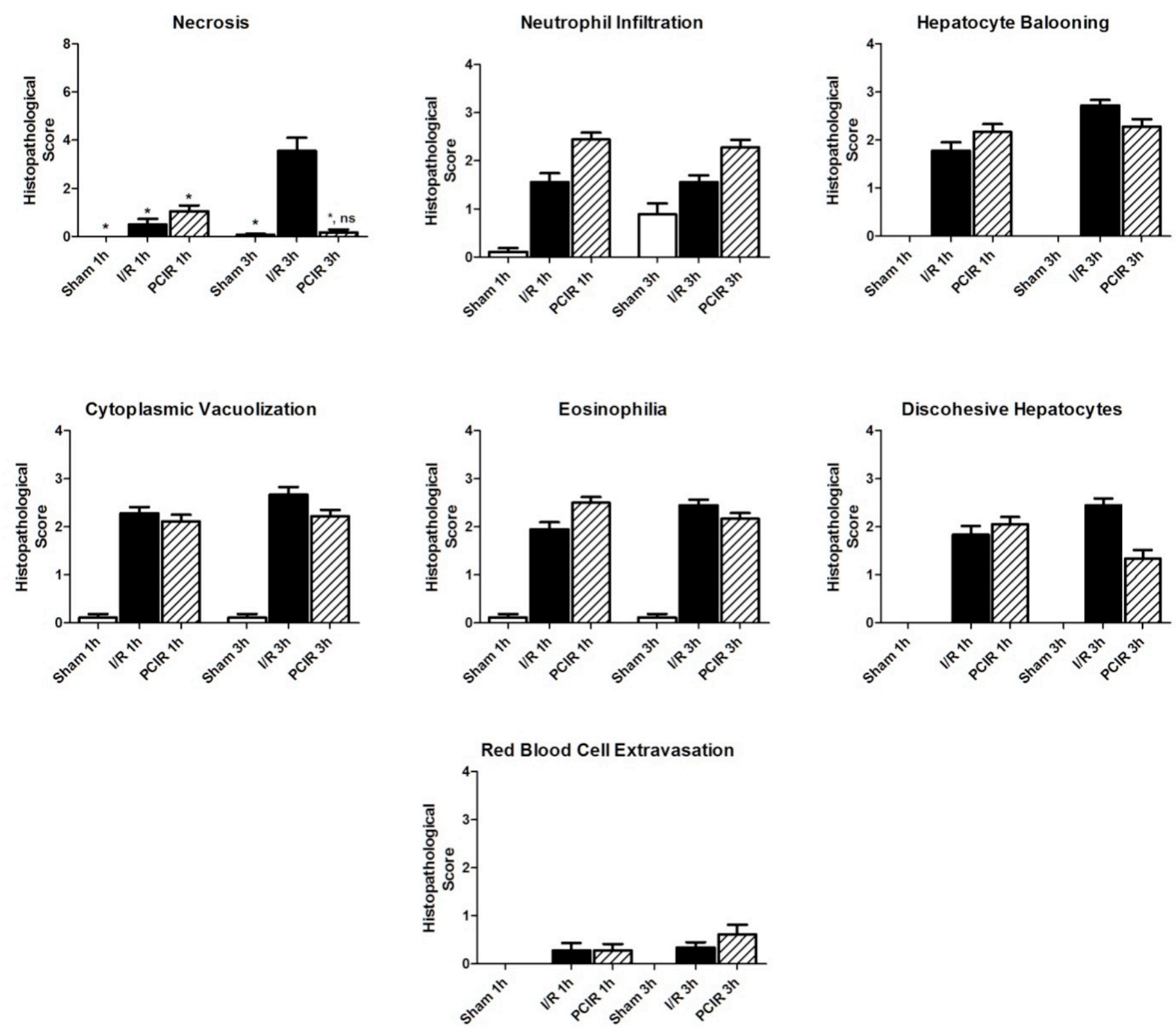

FIGURE 1 - Scores of histopathological features of liver injury. The bars represent the means \pm SEM (standard error of the mean) of fifteen digital images per animal in each group. $*(\mathrm{p}<0.005)$. 

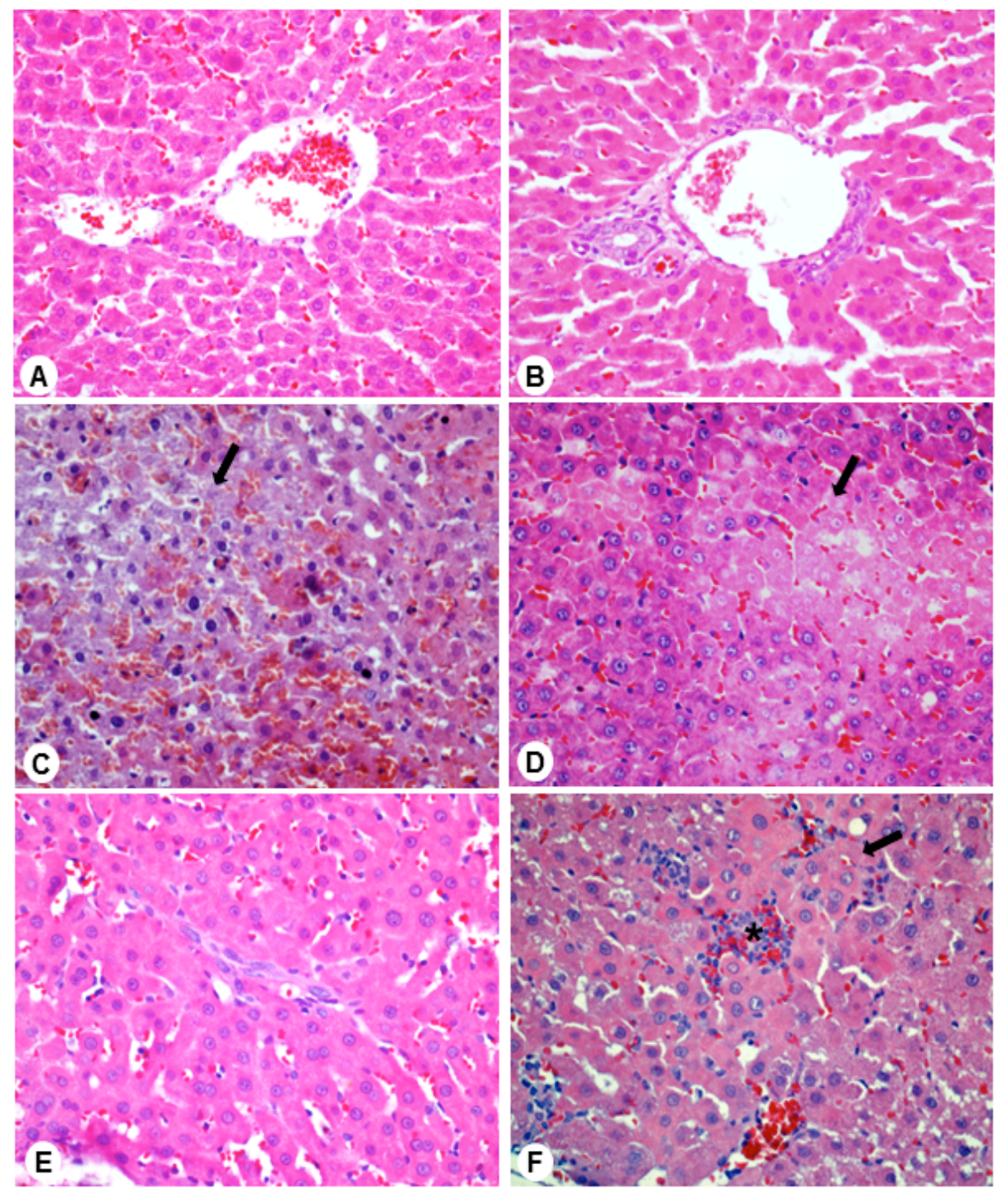

FIGURE 2 - Liver sections (H-E, x40). A and B. Sham group with normal liver parenchyma architecture; C. I/R group ( $1 \mathrm{~h}$ of reperfusion) showing reversible cellular injury (arrow); D. I/R group ( $3 \mathrm{~h}$ of reperfusion) showing extensive areas of eosinophilia (arrow); E. RIPC (1h of reperfusion) with a well-preserved tissue structure; F. RIPC (3h of reperfusion) showing some focal areas of cytoplasmic eosinophilia, mononuclear cells infiltration $(*)$, but without tissue necrosis.

\section{Hindlimb RIPC reduces plasma ALT levels}

The Sham group had minimal elevations in the ALT level. Higher values were observed in $\mathrm{I} / \mathrm{R}$ group, showing extensive hepatocellular injury. The RIPC group had a significant reduction in the ALT values in comparison to the I/R group (1h: $290.0 \pm$ 29.64 vs $315.8 \pm 35.88, \mathrm{p}<0.001$; 3h: $564.0 \pm 13.08$ vs $375.4 \pm$ 22.94, $\mathrm{p}<0.001$ ) (Figure 2).
ALT

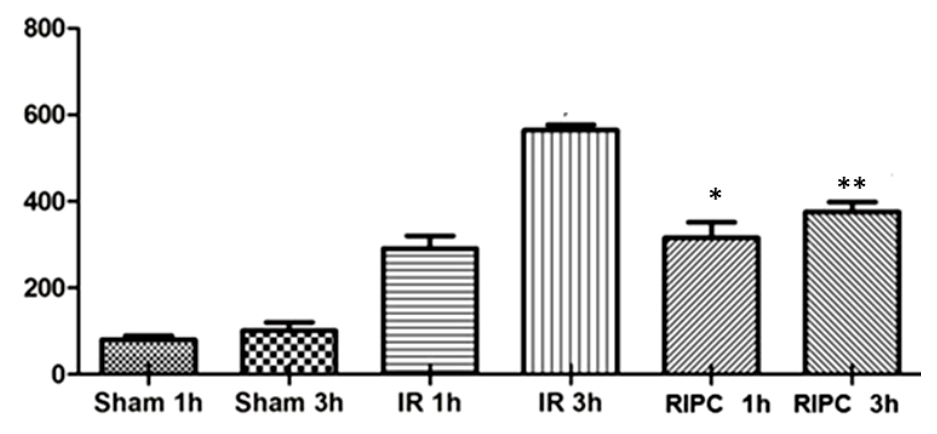

FIGURE 3 - Alanine aminotrasferase (ALT) plasma levels after $1 \mathrm{~h}$ and $3 \mathrm{~h}$ of liver reperfusion. Data are reported as means \pm SEM (standard error of the mean). ${ }^{*}(\mathrm{p}<0.001 \mathrm{I} / \mathrm{R} 1 \mathrm{~h} v s \mathrm{RIPC} 1 \mathrm{~h}) .{ }^{* *}(\mathrm{p}<0.01 \mathrm{I} / \mathrm{R} 3 \mathrm{~h} v s \mathrm{RIPC} 3 \mathrm{~h})$. 
RIPC increases the plasma IL-6 levels in the early phase of reperfusion but has no impact in IL-10 expression

The plasma cytokine measurements results are shown in Figure 4. IL-6 levels were significantly increased in the RIPC group after $1 \mathrm{~h}$ of reperfusion, in comparison to the $\mathrm{I} / \mathrm{R}$ group. $(432.1 \pm 40.48$ vs $273.4 \pm 14.33, \mathrm{p}<0.05)$. After $3 \mathrm{~h}$ of reperfusion there were also a significant reduction in IL-6 in the PCIR group (3h: $432.1 \pm 40.48$ vs $208.3 \pm 23.46, \mathrm{p}<0.001$ ).

The IL-10 measurements showed no significant difference between the groups (Figure 5).

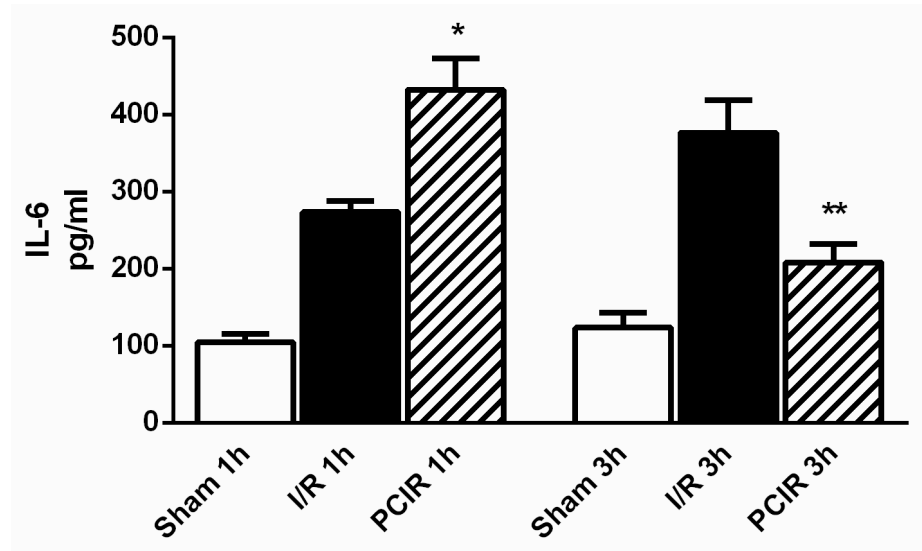

FIGURE 4 - IL-6 plasma levels after $1 \mathrm{~h}$ and $3 \mathrm{~h}$ of liver reperfusion. Data are reported as means \pm SEM (standard error of the mean). ${ }^{*} \mathrm{I} / \mathrm{R} 1 \mathrm{~h} v s$ RIPC 1h $(\mathrm{p}<0.05) .{ }^{* *}$ PCIR $1 \mathrm{~h}$ vs PCIR $3 \mathrm{~h}(\mathrm{p}<0.001)$.

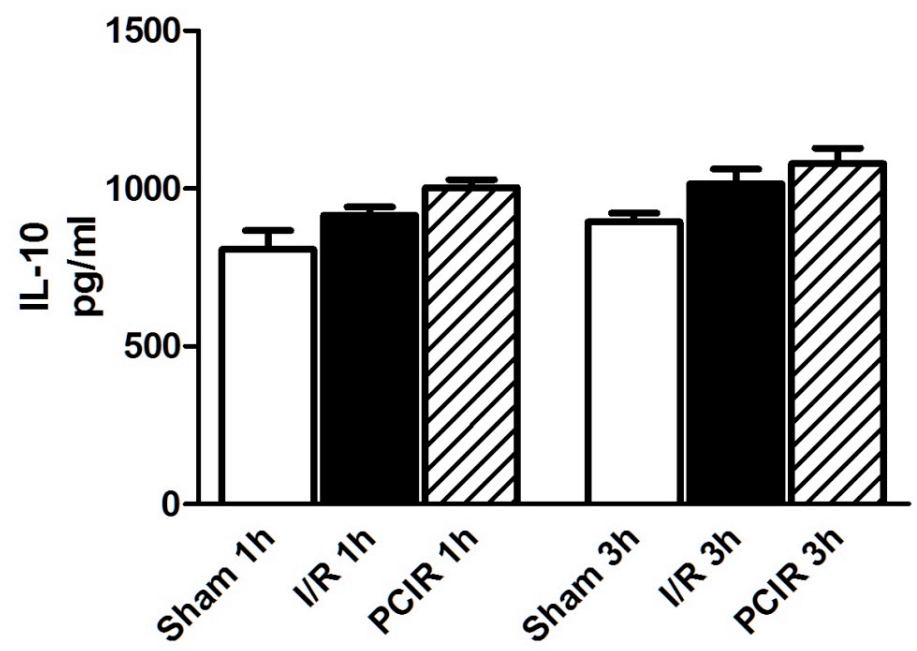

FIGURE 5 - IL-10 plasma levels after $1 \mathrm{~h}$ and $3 \mathrm{~h}$ of liver reperfusion. Data are reported as means $\pm \mathrm{SE}$ (standard error). The differences between the groups are not significant.

\section{Discussion}

In the present study we report the effects of RIPC in liver injury in a $70 \%$ ischemia/reperfusion rat model. We hypothesize RIPC modulates cytokine expression, in special IL-6 and IL-10, two cytokines with hepatoprotective effects. To the best of our knowledge this is the first paper to study the effect of RIPC in IL-6 and IL-10 expression in a liver IRI model.

RIPC is an organ preconditioning method originated from cardiovascular studies that only recently had been studied in the prevention of liver IRI. It has clear advantages when compared to PCI, as there is no occlusion of hilar vessels, no risk of vascular injury or ischemic stress to the graft, can be easily performed and does not interfere with the surgical field.

Several publications concerning the use of RIPC were published after the initial study of $\mathrm{Kanoria}^{7}$ and the results were encouraging, as liver protection form IRI was uniformly identified $^{7-10,15}$. Similar to these results, the present study demonstrates RIPC is effective in decreasing liver necrosis, as it shows a significant reduction of tissue necrosis in the RIPC group when compared to the I/R group (Figures 1 and 2). The ALT level, a well-known biochemical marker of liver injury, was also reduced in the RIPC group, corroborating the protective effect of RIPC in liver IRI (Figure 3).

Even though the beneficial effects of RIPC effects in the IRI had been clearly demonstrated, the underlying mechanisms involved are not completely elucidated. The physiological mechanism resulting in RIPC can be divided in three necessary steps: generation of mediators in the remote organ as a result of a brief ischemia-reperfusion stimulus; release of a signal (humoral, genetic, neural); and integration of that signal to the target tissue, triggering the molecular pathways leading to ischemia tolerance. It's possible RIPC shares molecular mechanisms with other conditioning approaches, like IPC, as they may have a common final effector pathway in the target organ ${ }^{17}$.

The liver has an unusually abundant population of lymphoid cell (Kupffer cells, NK cells and NK T cells) and has an important role in the immune system response to diverse noxious stimuli (ischemia, necrosis, tumors, microorganisms) ${ }^{18}$. These lymphoid cells take part in the systemic inflammatory response, as, after stimulation by circulating cytokines (IL-6, IL1 and TNFalpha), they induce the synthesis and systemic release of acute phase proteins. The Kupffer cells and liver resident lymphocytes also play an important central role in the local response to tissue damage during liver resection, transplantation, ischemiareperfusion and infection. 
The cytokines are most important mediators of these liver inflammatory pathways. They work in endocrine, paracrine and autocrine way in different cells, inducing cellular injury, limiting the inflammatory process by a negative feedback pathway and initiating the early steps in the regeneration process in the affected tissues.

All these observations make the cytokines an interesting candidate for a key mediator in RIPC. The molecular signals generated during the muscular ischemic insult may modulate the release of circulating cytokines and modify the remote organ response to an ischemic insult. The cytokines can also act in the remote tissue as a local mediator of the RIPC protective effect. In fact, in a study by Konstantinov et al. ${ }^{19}$, after a RIPC protocol, a microarray of genes involved in the inflammatory response (leukocyte adhesion, chemotaxis and migration, cytokines productions) showed that genes with pro-inflammatory actions were down-regulated and genes with anti-inflammatory properties were up-regulated, illustrating the close relationship between the RIPC and the immune system mediators.

Interlukin-6 is a pleiotropic cytokine with an important role in hematopoiesis, host defense, inflammation and tissue regeneration. After a systemic insult, IL-6 is released into the circulation and stimulates liver cells to secrete acute phase proteins, playing a relevant role in the systemic inflammatory response syndrome. The liver is capable of producing IL-6: after an injury, Kupffer cells and other immune cells located in the liver tissue release IL- 6 that acts at a paracrine manner. This classical concept was challenged recently by a study showing that hepatocytes also take a significant part in the IL-6 production in response to different stimuli, stressing the complexities of IL-6 actions in the liver ${ }^{20}$.

Several research groups studied the cytokine response to the liver IRI and the effect of preconditioning strategies in the cytokine expression profile ${ }^{21-24}$. Teoh et al. ${ }^{25}$ compared the plasma IL-6 levels in naïve and IPC groups. The results indicated that in both groups there was a rise in serum IL-6 after 120 minutes of reperfusion, but it was significant higher in the IPC group. The authors also administered low doses of recombinant IL-6 prior to the ischemic insult in another group. It resulted in significant attenuated liver injury, similar to the observed in the IPC group, corroborating the hypothesis of a protective effect of IL-6 in IRI. Camargo et al..$^{22}$ employed IL-6 deficient mice (-/-), that were pre-treated with recombinant IL-6 prior to the ischemic injury, to evaluate the role of IL-6 in liver IRI and its effect in TNF-alpha mRNA expression, C-reactive protein (CRP) and hepatocyte proliferation. The results showed a lesser degree of liver injury, as measured by histological study and serum ALT, and lower serum CPR and a lower expression of TNF-alpha mRNA in the IL-6 deficient mice. The authors concluded IL- 6 has protective effect in liver IRI by means of an anti-inflammatory action, as there was a significant reduction in TNF-alpha mRNA and serum CRP.

In the present study, using a RIPC strategy, we also observed a significant higher level of plasma IL-6 in the study group, but at an earlier point (60 minutes of reperfusion) when compared to the IPC studies. Corroborating our findings, other studies using RIPC, but in different experimental models, also identified an elevation of IL-6 serum levels and IL-6 mRNA ${ }^{15,16}$. We can speculate this early peak of serum IL-6 is the result of its role in an initial step of the RIPC mechanism, probably as the signal conveyed by the remote ischemic site to the target organ, but further studies are warranted to test this hypothesis.

Interleukin-10 is another important cytokine involved in liver IRI. It acts as a potent anti-inflammatory cytokine and it is one of the most important mediators of the negative feedback pathway that regulates the innate immune response ${ }^{11}$. It has been demonstrated IL-10 levels have an indirect correlation to liver $\mathrm{IRI}^{26,27}$ and recombinant IL-10 administration had a protective effect in liver IRI models ${ }^{28}$. These observations make IL-10 an attractive candidate for a mediator of RIPC-induced ischemic tolerance.

In our model there was no difference in IL-10 serum levels between the I/R and the RIPC groups. There are few papers studying IL-10 expression in RIPC models. Recently Oberkofler et al. ${ }^{29}$ evaluated gene expressions in target organs 60 minutes after RIPC, but before the I/R injury were induced in the target organs. The goal was to identify the molecular signals that could induce the remote organ protection. Il-10 was one of the genes that showed an augmented expression. It is difficult to compare these results to our study, as there are relevant differences in the experimental design: our study used different time points for the cytokine assessment and, most important, in our study the sampling took place after a 45-minute liver ischemia, what can change cytokine expression. Another paper studying RIPC and IL-10, in myocardial protection model, demonstrated that IL-10 plasma and myocardial levels were elevated 24 hours of reperfusion ${ }^{30}$, suggesting IL-10 elevation might be a late event in the RIPC.

Our results corroborate the protective effect of RIPC on the liver IRI that had been identified by previously published papers and point the need for a clinical trial evaluating RIPC in liver surgery. RIPC is an attractive strategy in the clinical setting because it is a simple and non-invasive technique that can be performed in a non-invasive manner using a sphygmomanometer's 
cuff. Our findings also suggest that IL-6 might have an important role in the physiological processes implicated in the RIPC. The IL-10 role was not elucidated, and remains the question whether it is not involved in RIPC mechanism (what is improbable) or the changes in IL-10 expression is beyond the study time points.

The study design has certain limitations that should be mentioned. First, the RIPC effects on the late phase of reperfusion were not evaluated, as our last time point was 180 minutes. The long-term effects on cytokine expression remain unknown. Cytokine assessment did not include mRNA measurements or the mediators downstream in the cytokine's pathways (like STAT3 or NFKB), so a complete understanding of the molecular mediators involved in the IL-6 and IL-10 actions were not possible.

\section{Conclusion}

Remote ischemic preconditioning is an effective reducing liver necrosis in a rat model of ischemia-reperfusion. It also shows that RIPC mediates a peak of IL-6 expression that take place in an earlier period than the observed in IPC studies.

\section{References}

1. Hammond JS, Guha IN, Beckingham IJ, Lobo DN. Prediction, prevention and management of postresection liver failure. Br J Surg. 2011 Sep;98(9):1188-200. doi: 10.1002/bjs.7630.

2. de Rougemont O, Dutkowski P, Clavien PA. Biological modulation of liver ischemia-reperfusion injury. Curr Opin Organ Transplant. 2010 Apr;15(2):183-9. doi: 10.1097/MOT.0b013e3283373ced.

3. Murry CE, Jennings RB, Reimer KA. Preconditioning with ischemia: a delay of lethal cell injury in ischemic myocardium. Circulation. 1986 Nov;74(5):1124-36. PMID: 3769170.

4. Theodoraki K, Tympa A, Karmaniolou I, Tsaroucha A, Arkadopoulos N, Smyrniotis V. Ischemia/reperfusion injury in liver resection: a review of preconditioning methods. Surg Today. 2011 May;41(5):620-9. doi: 10.1007/s00595-010-4444-4.

5. O'Neill S, Leuschner S, McNally SJ, Garden OJ, Wigmore SJ, Harrison EM. Meta-analysis of ischaemic preconditioning for liver resections Br J Surg. 2013 Dec;100(13):1689-700. doi: 10.1002/ bjs. 9277

6. Przyklenk K, Bauer B, Ovize M, Kloner RA, Whittaker P. Regional ischemic 'preconditioning' protects remote virgin myocardium from subsequent sustained coronary occlusion. Circulation. 1993 Mar;87(3):893-9. PMID: 7680290.

7. Kanoria S, Jalan R, Davies NA, Seifalian AM, Williams R, Davidson $\mathrm{BR}$. Remote ischaemic preconditioning of the hind limb reduces experimental liver warm ischaemia-reperfusion injury. Br J Surg. 2006 Jun;93(6):762-8. PMID: 16609953.

8. Tapuria N, Junnarkar SP, Dutt N, Abu-Amara M, Fuller B, Seifalian $\mathrm{AM}$, et al. Effect of remote ischemic preconditioning on hepatic microcirculation and function in a rat model of hepatic ischemia reperfusion injury. HPB (Oxford). 2009 Mar;11(2):108-17. doi: 10.1111/j.1477-2574.2009.00006.x.

9. Wang N, Lu JG, He XL, Li N, Qiao Q, Yin JK, Ma QJ. Effects of ischemic postconditioning on reperfusion injury in rat liver grafts after orthotopic liver transplantation. Hepatol Res. 2009 Apr;39(4):382-90. doi: 10.1111/j.1872-034X.2008.00462.x.

10. Abu-Amara M, Yang SY, Quaglia A, Rowley P, Tapuria N, Seifalian AM, Fuller BJ, Davidson BR. Effect of remote ischemic preconditioning on liver ischemia/reperfusion injury using a new mouse model. Liver Transpl. 2011 Jan;17(1):70-82. doi: 10.1002/ 1t.22204.

11. Lim SY, Hausenloy DJ. Remote ischemic conditioning: from bench to bedside. Front Physiol. 2012 Feb 20;3:27. doi: 10.3389/ fphys.2012.00027. eCollection 2012

12. Abu-Amara M, Yang SY, Tapuria N, Fuller B, Davidson B, Seifalian A. Liver ischemia/reperfusion injury: processes in inflammatory networks--a review. Liver Transpl. 2010 Sep;16(9):1016-32. PMID: 20818739.

13. Marques RG, Petroianu A. A new Brazilian law for scientific use of animals. Acta Cir Bras. 2009. Jan-Feb;24(1):69-74. PMID: 19169547.

14. Yamauchi H, Baca I, Mittmann U, Geisen HP, Salzer M. Postischemic liver damage in rats: effect of some therapeutic interventions on survival rate. The Tohoku J Exp Med. 1982;138(1):63-70. PMID: 6293117

15. Wang M, Shen J, Feng B, Gui L, Chen Q, Zhang B, Tang J, Li $\mathrm{X}$. Remote ischemic preconditioning promotes early liver cell proliferation in a rat model of small-for-size liver transplantation. J Surg Res. 2013 Jan;179(1):e245-53. doi: 10.1016/j.jss.2012.02.007.

16. Leal AJ, Tannuri AC, Belon AR, Guimarães RR, Coelho MC, Gonçalves J de O, Serafini S, Melo ES, Tannuri U. Effects of ischemic preconditioning in a pig model of large-for-size liver transplantation. Clinics (Sao Paulo). 2015 Feb;70(2):126-35. doi: 10.6061/clinics/2015(02)10.

17. Anrather J, Hallenbeck JM. Biological networks in ischemic tolerance - rethinking the approach to clinical conditioning. Transl Stroke Res. 2013 Feb;4(1):114-29. doi: 10.1007/s12975-0120244-z.

18. Crispe IN. The liver as a lymphoid organ. Annu Rev Immunol. 2009;27:147-63. doi: 10.1146/annurev.immunol.021908.132629.

19. Konstantinov IE, Arab S, Kharbanda RK, Li J, Cheung MM, Cherepanov V, Downey GP, Liu PP, Cukerman E, Coles JG, Redington AN. The remote ischemic preconditioning stimulus modifies inflammatory gene expression in humans. Physiol Genomics. 2004 Sep 16;19(1):143-50. PMID: 15304621.

20. Norris CA, He M, Kang LI, Ding MQ, Radder JE, Haynes MM, Yang Y, Paranjpe S, Bowen WC, Orr A, Michalopoulos GK, Stolz DB, Mars WM. Synthesis of IL-6 by hepatocytes is a normal response to common hepatic stimuli. PLoS One. 2014 Apr 24;9(4):e96053. doi: 10.1371/journal.pone.0096053. eCollection 2014.

21. Matsumoto T, O'Malley K, Efron PA, Burger C, McAuliffe PF, Scumpia PO, et al. Interleukin-6 and STAT3 protect the liver from hepatic ischemia and reperfusion injury during ischemic preconditioning. Surgery. 2006 Nov;140(5):793-802. PMID: 17084723.

22. Camargo CA, Jr., Madden JF, Gao W, Selvan RS, Clav ien PA. Interleukin-6 protects liver against warm ischemia/reperfusion injury and promotes hepatocyte proliferation in the rodent. Hepatology. 1997 Dec;26(6):1513-20. PMID: 9397992.

23. Tiberio L, Tiberio GA, Bardella L, Cervi E, Cerea K, Dreano M, Garotta G, Fra A, Montani N, Ferrari-Bravo A, Callea F, Grigolato P, Giulini SM, Schiaffonati L. Mechanisms of interleukin-6 protection against ischemia-reperfusion injury in rat liver. Cytokine. 2006 May;34(3-4):131-42. PMID: 16814559.

24. Haga S, Terui K, Zhang HQ, Enosawa S, Ogawa W, Inoue H, Okuyama T, Takeda K, Akira S, Ogino T, Irani K, Ozaki M. Stat3 protects against Fas-induced liver injury by redox-dependent and 
-independent mechanisms. J Clin Invest. 2003 Oct;112(7):989-98. PMID: 14523036.

25. Teoh NC. Hepatic ischemia reperfusion injury: Contemporary perspectives on pathogenic mechanisms and basis for hepatoprotection-the good, bad and deadly. J Gastroenterol Hepatol. 2011;26 Suppl 1:180-7. Epub 2011/01/14.

26. Ji H, Shen X, Gao F, Ke B, Freitas MC, Uchida Y, Busuttil RW, Zhai Y, Kupiec-Weglinski JW. Programmed death-1/B7-H1 negative costimulation protects mouse liver against ischemia and reperfusion injury. Hepatology. 2010;52(4):1380-9. Epub 2010/09/04.

27. Ke B, Shen XD, Tsuchihashi S, Gao F, Araujo JA, Busuttil RW, Ritter T, Kupiec-Weglinski JW. Viral interleukin-10 gene transfer prevents liver ischemia-reperfusion injury: Toll-like receptor-4 and heme oxygenase-1 signaling in innate and adaptive immunity. Hum Gene Ther. 2007;18(4):355-66. PMID: 17439357.

28. Dinant S, Vetelainen RL, Florquin S, van Vliet AK, van Gulik TM. IL-10 attenuates hepatic I/R injury and promotes hepatocyte proliferation. J Surg Res. 2007 Aug;141(2):176-82. PMID: 17543989.

29. Oberkofler CE, Limani P, Jang JH, Rickenbacher A, Lehmann K, Raptis DA, Ungethuem U, Tian Y, Grabliauskaite K, Humar R, Graf R, Humar B, Clavien PA. Systemic protection through remote ischemic preconditioning is spread by platelet-dependent signaling in mice. Hepatology. 2014 Oct;60(4):1409-17. doi: 10.1002/ hep. 27089 .

30. Cai ZP, Parajuli N, Zheng X, Becker L. Remote ischemic preconditioning confers late protection against myocardial ischemiareperfusion injury in mice by upregulating interleukin-10. Basic Res Cardiol. 2012 Jul;107(4):277. doi: 10.1007/s00395-012-0277-1.

\section{Correspondence:}

Marcos Bettini Pitombo

Departamento de Cirurgia Geral

Hospital Universitário Pedro Ernesto

Boulevard 28 de Setembro, $77 / 4^{\circ}$ andar

20551-030 Rio de Janeiro - RJ Brasil

Tel./Fax: (55 21)2868-8062

mac.guimaraes@gmail.com

Received: March 7, 2015

Review: May 12, 2015

Accepted: June 9, 2015

Conflict of interest: none

Financial source: Fundação Carlos Chagas Filho de Amparo à Pesquisa do Estado do Rio de Janeiro (FAPERJ)

${ }^{1}$ Research performed at Laboratory of Experimental Surgery, Department of General Surgery, Universidade Estadual do Rio de Janeiro (UERJ), Brazil. Part of Master degree thesis, Postgraduate Program in Pathophysiology and Surgical Sciences, UERJ. Tutor: Marco Bettini Pitombo. 